\title{
Coronary artery spasm of different degrees as cause of angina at rest with ST segment depression and elevation
}

\author{
STEFANO DE SERVI, GIUSEPPE SPECCHIA, AND LUIGI ANGOLI \\ From Divisione di Cardiologia, Policlinico S. Matteo, Pavia, Italy
}

SUMMARY Chest pain induced by ergometrine was associated with ST depression and subsequent elevation in anterior leads in a 42-year-old man suffering from angina at rest. Coronary arteriography during the attack showed that coronary arterial spasm of different degrees was responsible for chest pain and both types of electrocardiographic abnormality.

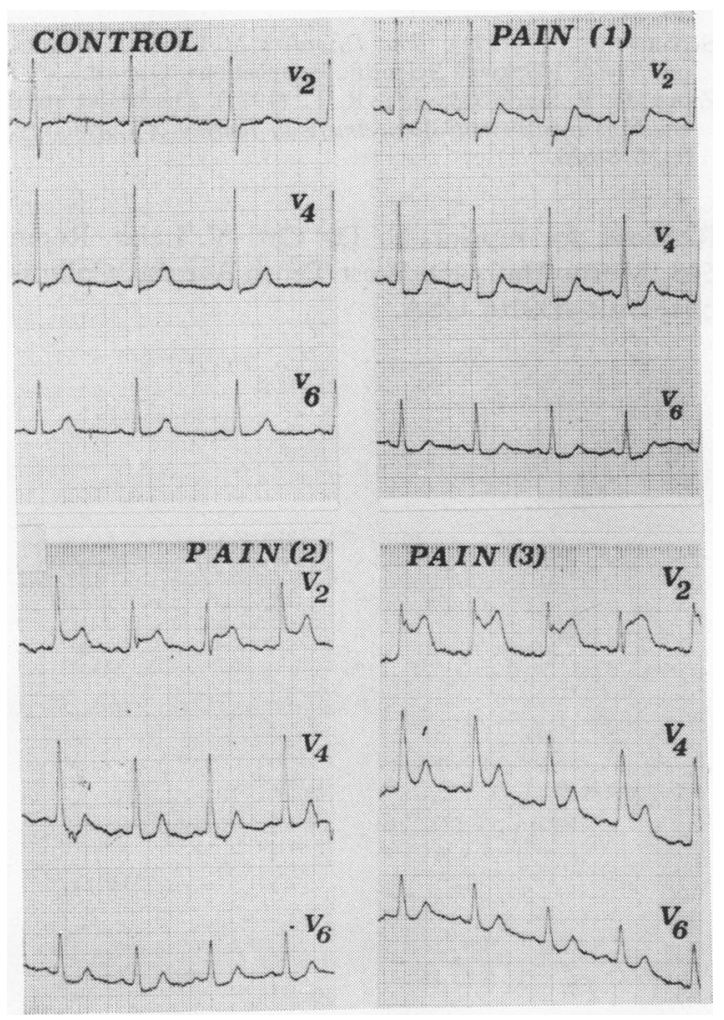

Fig. 1 Electrocardiogram (leads V2, V4, and V6) during progressive development of chest pain associated with spasm of the left anterior descending coronary artery induced by ergometrine. Note $S T$ segment depression in leads V2,V4, and V6 (1), and subsequent $S T$ elevation in $V 2(2)$, and in $V 2$ and $V 4$ (3).
Although it is now firmly established that coronary arterial spasm is responsible for the severe ischaemia occurring in patients with variant angina pectoris (MacAlpin et al., 1973; Oliva et al., 1973; Maseri et al., 1975), it is not yet clear whether or not it may also play a role in angina associated with ST depression.

We describe a patient suffering from angina at rest in whom ergometrine maleate could elicit an anginal attack associated initially with ST depression and subsequently with elevation in the same leads. Coronary arteriography performed during pain showed that coronary arterial spasm was the underlying pathogenetic mechanism of chest pain and both types of electrocardiographic abnormality.

\section{Case report}

A 48-year-old man had a 1-year history of oppressive anterior chest pain with radiation to the neck and arms. The pain occurred at rest and occasionally with exertion and was relieved by glyceryl trinitrate. The patient gave no history of hypertension or diabetes mellitus. He smoked between 10 and 20 cigarettes daily.

There was no abnormality on physical examination. Blood count, urine analysis, routine biochemical estimations, and lipid profile were normal. Chest $x$-ray film showed a normal heart size. The resting electrocardiogram showed slight depression of ST segments in leads I, II, and V1 to V3. Electrocardiogram taken during a spontaneous attack of pain showed conspicuous ST depression in leads I, II, and V2 to V6. Electrocardiogram during 


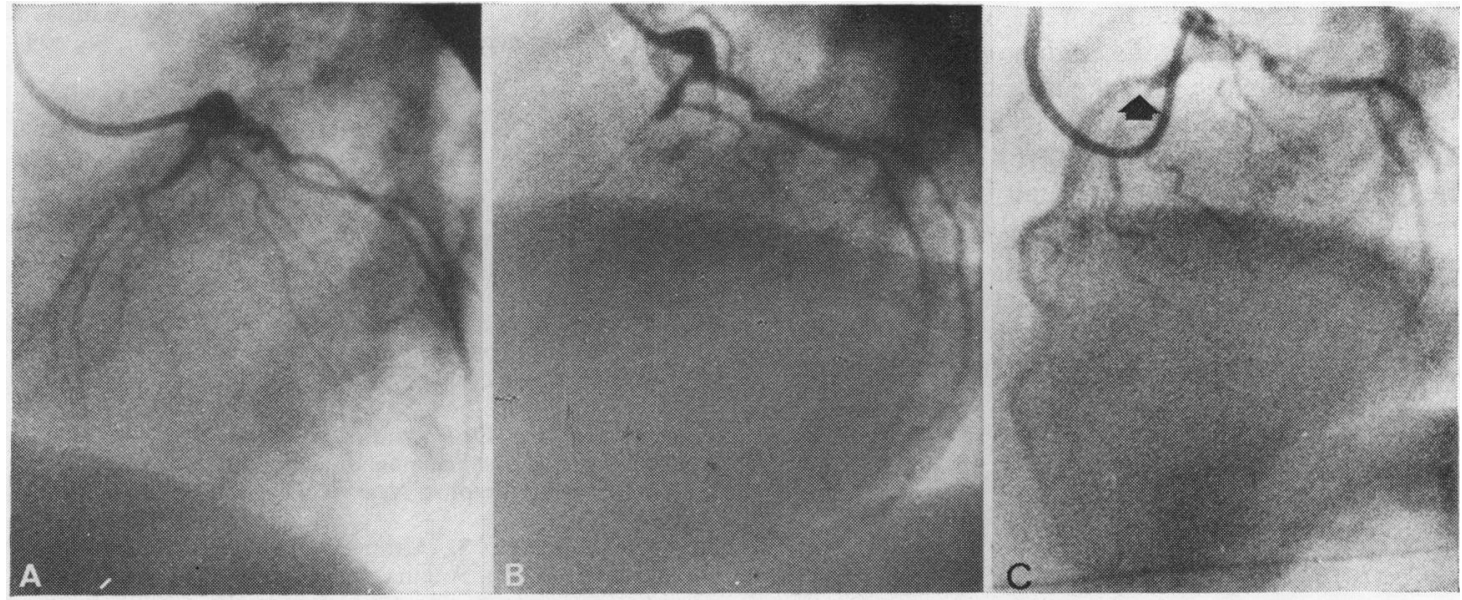

Fig. 2 Left coronary arteriograms in the left anterior oblique projection. $(A)$ During pain associated with $S T$ depression. (B) During pain associated with ST elevation. (C) After the sublingual administration of glyceryl trinitrate. Note the progression of vascular spasm from $A$ to $B$ with occlusion of the left anterior descending coronary artery. Repeat injection after glyceryl trinitrate shows reversal of coronary arterial spasm and a mild (50\%) fixed stenosis (arrow).

a graded exercise test on a bicycle ergometer showed no ischaemic changes.

Left heart catheterisation showed pressures in the left ventricle of $120 / 10 \mathrm{mmHg}$ and in the ascending aorta of $120 / 80 \mathrm{mmHg}$. Selective coronary cineangiograms obtained by the Sones technique disclosed a mild $(50 \%)$ focal narrowing of left anterior descending coronary artery and a normal right coronary artery. Because the organic lesion was unlikely to have been responsible for the clinical symptoms, ergometrine maleate $(0.2 \mathrm{mg})$ was administered intravenously in an attempt to provoke coronary artery spasm. Chest pain and ST depression in leads V2, V4, and V6 developed one minute after the administration of the drug. A selective left coronary artery injection during pain showed spastic obstruction without occlusion at the site of the stenosis, with slow passage of contrast medium which did not reach the apex. The chest pain persisted and the electrocardiogram now showed ST elevation in leads V2 and V4. Another left coronary artery injection at this time showed further reduction in the calibre of the left anterior descending artery and more proximal occlusion of the vessel. After sublingual administration of glyceryl trinitrate the pain subsided and the displaced ST segment returned to the isoelectric line. Left coronary arteriogram now showed no evidence of vascular spasm.

\section{Discussion}

Angina at rest may be associated with ST segment elevation or depression, and in some cases both ST elevation and at other times ST depression have occurred in the same patient (Jouve et al., 1969; Maseri et al., 1977a). Thallium-201 scintigraphy has shown a transmural reduction of regional perfusion during ST elevation suggesting extensive myocardial ischaemia (Maseri et al., 1976), while ST depression appears to be related to subendocardial or diffuse ischaemia (Parodi et al., 1977). Coronary artery spasm is accepted as the mechanism of recurrent episodes of chest pain with ST elevation, but the mechanism of rest pain with ST depression remains uncertain. However, the occurrence of coronary artery spasm has been reported in patients with subendocardial ischaemia during pain (Wiener et al., 1976; Maseri et al., 1977a). Marzilli et al. (1977) have described spasm of a small coronary artery branch or a diffuse narrowing of several branches during attacks of angina associated with ST depression.

In this patient we were able to induce an attack of angina by injecting ergometrine maleate. It is well known that this drug can provoke coronary arterial spasm and reproduce the clinical and electrocardiographic patterns of spontaneous angina (Specchia et al., 1976; Schroeder et al., 1977). Coronary arteriography performed during the attack associated with ST depression showed spastic obstruction of the left anterior descending artery at the site of an insignificant fixed stenosis. When ST segment elevation occurred we were able to demonstrate more severe spasm which resulted in further reduction in 
calibre of the vessel and more proximal occlusion. The fact that spontaneous angina occurred with ST depression while the provoked attack was associated with both ST depression and elevation can be explained by the very powerful vasoconstrictor effect of the drug or by the usually prompt administration of glyceryl trinitrate at the onset of spontaneous pain.

The occurrence in this case of angina at rest with ST elevation or depression supports the hypothesis that coronary arterial spasm of differing degrees may be responsible for both types of electrocardiographic change. Thus, ST elevation and ST depression seem to represent two electrocardiographic aspects of 'the continuous spectrum of vasospastic angina' (Maseri et al., 1977b).

We also reaffirm the usefulness of the ergometrine test during coronary arteriography in shedding light on the pathogenetic mechanism of angina at rest in patients who have no significant organic narrowing of coronary arteries.

\section{References}

Jouve, A., Guiran, J. B., Viallet, H., Gras, A., Blanc, M., Arnoux, M., Rouvier, M., and Brunel, J. C. (1969). Les modifications électrocardiographiques au cours des crises d'angor spontané. Archives des Maladies du Coeur et des Vaisseaux, 62, 331-351.

MacAlpin, R. N., Kattus, A. A., and Alvaro, A. B. (1973). Angina pectoris at rest with preservation of exercise capacity: Prinzmetal variant angina. Circulation, 47, 946958.

Marzilli, M., L'Abbate, A., Ballestra, A. M., and Maseri, A. (1977). Coronary angiographic findings during angina at rest with ST depression (abstract). Circulation, 55 and 56, Suppl. III, 83.

Maseri, A., Mimmo, R., Chierchia, S., Marchesi, C., Pesola,
A., and L'Abbate, A. (1975). Coronary artery spasm as a cause of acute myocardial ischemia in man. Chest, 68, 625633.

Maseri, A., Parodi, O., Severi, S., and Pesola, A. (1976). Transient transmural reduction of myocardial blood flow, demonstrated by thallium-201 scintigraphy as a cause of variant angina. Circulation, 54, 280-288.

Maseri, A., Pesola, A., Marzilli, M., Severi, S., Parodi, O., L'Abbate, A., Ballestra, A. M., Maltinti, G., De Nes, D. M., and Biagini, A. (1977a). Coronary vasospasm in angina pectoris. Lancet, 1, 713-717.

Maseri, A., Severi, S., L'Abbate, A., and Pesola, A. (1977b). Variant angina: one aspect of a continuous spectrum of vasospastic angina (abstract). Circulation, 55 and 56, Suppl. III, 33.

Oliva, P. B., Potts, D. E., and Pluss, R. G. (1973). Coronary arterial spasm in Prinzmetal angina: documentation by coronary arteriography. New England fournal of Medicine, 288, 745-751.

Parodi, O., Severi, S., Uthurralt, N., Solfanelli, S., and Maseri, A. (1977). Angina pectoris at rest: regional myocardial perfusion during ST segment elevation or depression (abstract). Circulation, 55 and 56, Suppl. III, 229.

Schroeder, J. S., Bolen, J. L., Quint, R. A., Clark, D. A., Hayden, W. G., Higgins, C. B., and Wexler, L. (1977). Provocation of coronary spasm with ergonovine maleate. American fournal of Cardiology, 40, 487-491.

Specchia, G., Angoli, L., De Servi, S., Mussini, A., Bramucci, E., Marinoni, G. P., Ray, M., Montemartini, C., D Guglielmo, L., and Bobba, P. (1976). Spasmo coronarico indotto dalla somministrazione di ergonovina maleato in soggetti affetti da angina spontanea. Giornale Italiano di Cardiologia, 6, 1177-1183.

Wiener, L., Kasparian, H., Duca, P. R., Walinsky, P., Gottlieb, R. S., Hanckel, F., and Brest, A. N. (1976). Spectrum of coronary arterial spasm. Clinical, angiographic and myocardial metabolic experience in 29 cases. American fournal of Cardiology, 38, 945-955.

Requests for reprints to Professor Giuseppe Specchia, Divisione di Cardiologia, Policlinico S. Matteo, 27100 Pavia, Italy. 